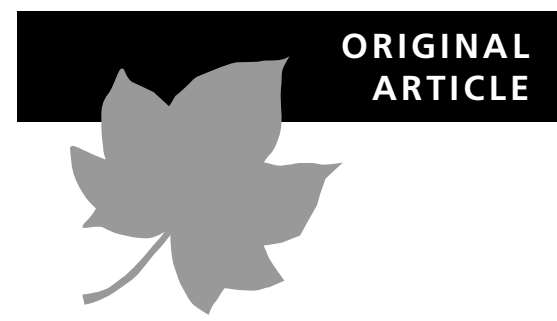

\title{
Phylogeography of Trochodendron aralioides (Trochodendraceae) in Taiwan and its adjacent areas
}

Shing-Fan Huang ${ }^{1}$, Shih-Ying Hwang ${ }^{2}$, Jenn-Che Wang ${ }^{3}$ and Tsan-Piao $\operatorname{Lin}^{1 \star}$

${ }^{1}$ Institute of Plant Biology, National Taiwan University, Taipei, ${ }^{2}$ Graduate Institute of Biotechnology, Chinese Culture University, Yangmingshan, Taipei, and ${ }^{3}$ Department of Biology, National Taiwan Normal University, Taipei, Taiwan
${ }^{*}$ Correspondence: Tsan-Piao Lin, National Taiwan University, Institute of Plant Biology, Roosevelt Road, Section 4, Taipei, Taiwan 106. E-mail: tpl@ntu.edu.tw

\section{ABSTRACT}

Aim This paper described current phylogeographical patterns of chloroplastic DNA variation of Trochodendron aralioides, a temperate tree species, and inferred its possible refugium in Taiwan. This information was compared with the known phylogeographical pattern of subtropical tree species.

Location A total of 24 populations were sampled including 20 from Taiwan, two each from the Ryukyus and Japan.

Methods A haplotype network was constructed by computer program TCS, various parameters of genetic diversity were calculated and neutrality was tested by computer program DnaSP. To examine the similarity of genetic structure among populations, a maximum parsimony tree was reconstructed by computer program PAUP*. The results of isozyme of $T$. aralioides from a previous publication were incorporated into this study to infer the phylogeographical history.

Results Nine haplotypes according to six substitutions, two indels and one inversion of the two cpDNA intergenic spacer fragments (pet $\mathrm{G}-\operatorname{trn} \mathrm{P}$ and petA$p s b J)$ of $T$. aralioides were recognized. Genetic structure of the population of Japan is totally different from those of Taiwan and the Ryukyus. In Taiwan, the genetic structure was differentiated among populations revealed by $G_{\text {st }}=0.700$ and $N_{\mathrm{st}}=0.542$, and the population genetics was clearly spatially structured. Two population groups were recognized. The first group was distributed islandwide and extended to the Ryukyus. The second group contained five of the seven known haplotypes, and was restricted to the area between latitude $24^{\circ} 46^{\prime}$ and $24^{\circ} 06^{\prime} \mathrm{N}$.

Conclusions In Taiwan, north-central area between latitude $24^{\circ} 46^{\prime}$ and $24^{\circ} 06^{\prime} \mathrm{N}$ is potentially a refugium during the last glaciations. This finding is contradicted to subtropical species as Cyclobalanopsis glauca.

\section{Keywords}

cpDNA, phylogeography, refugium, Taiwan, Trochodendron aralioides.

\section{INTRODUCTION}

Phylogeography (Avise et al., 1987) is a branch of historical biogeography that involves determining the history of taxa in space and time by integrating the phylogenetic and geographical patterns. This is carried out especially at the level of species complex or intraspecific populations to reveal how the present distribution patterns of taxa have been shaped by geological events or other factors. As the taxon is at species level, the scale in time and space is much shorter and smaller than the study of generic or higher taxonomic levels, and is suitable for revealing the taxon's history from the Quaternary, < 2 Myr.

The origin of the island Taiwan can be traced to the Pliocene, about 4-5 Ma, when it began to emerge. Taiwan quickly became the present shape at about $2 \mathrm{Ma}$ through mountain building (Ho, 1982; Shaw, 1996). It is thus suitable to study Taiwan's species based on phylogeography. Taiwan 
hosts more than 4000 species of vascular plants distributed from the sea level to $3900 \mathrm{~m}$ in elevation (Hsieh, 2002), and most of them are distributed within one of three floristic regions delimited altitudinally (Hsieh et al., 1994).

Trochodendron aralioides, the only extant member of Trochodendron, is distributed in Japan, the Ryukyus and Taiwan (Wu et al., 2001). It is mostly related to Tetracentron based on DNA markers including 5.8S nuclear ribosomal (nr)DNA, $\operatorname{trn} \mathrm{L}$ intron chloroplast (cp)DNA and $r b c \mathrm{~L}-a t p \mathrm{~B}$ intergenic spacer cpDNA (Wu et al., 1999; Wu, 2001). These two genera are either grouped as the family Trochodendraceae or recognized in the separate families Trochodendraceae and Tetracentraceae, and have been considered as primitive in Hamamelididae ( $\mathrm{Lu}$ et al., 1993). The species T. aralioides is characterized by tree habit with vesselless wood, alternate leaves in pseudowhorled arrangement, flowers without sepals and petals, stamens in three to four whorls, and many fused carpels with free stigmas. The flowers are dichogamous, selfincompatible and obligatorily xenogamous (Chaw, 1992). Two main population groups were distinguished in T. aralioides based on the analyses of genetic variation of allozyme and sequence of internal transcribed spacer $\operatorname{nrDNA}(\mathrm{Wu}$ et al., 2001; Wu, 2001). The first group includes populations from Japan and Amami Island, central Ryukyu, and the second group includes the populations from Taiwan and the Iriomote Island, southern Ryukyu. In Taiwan, T. aralioides has a wide distribution from north to south and across a range of elevations. It is distributed up to $3000 \mathrm{~m}$ in the Central Mountain Range in the cloud-foggy zone of relatively cold mountain forest. In the north and south, it inhabits 400$1000 \mathrm{~m}$ in elevation in subtropical evergreen broad-leaved forest. Two population groups of T. aralioides were recognized in Taiwan based on the allelic frequencies of allozyme, i.e. north, and south-central (Wu et al., 2001). The results of the analyses are summarized as follows: (i) the genetic diversity is higher in central Taiwan, and (ii) the genetic variation comes from within areas $\left(F_{\mathrm{st}}=0.1 ; F_{\mathrm{st}}\right.$ represents degree of differentiation between populations estimated from 0 to 1 . Value of 0.1 stands for weak differentiation between populations and this may be due to outcrossing which is the case in Trochodendron as mentioned earlier) rather than among them. The mating system of Trochodendron is very special as the flowers are self-incompatible and obligatorily xenogamous (Chaw, 1992). This might contribute to the reduced differentiation between populations.

An integration of the history of species representative of different elevations may give insight into understanding the consensus history of the vascular plants in Taiwan. So far, a subtropical species, Cyclobalanopsis glaua, Fagaceae (Huang et al., 2002) and a temperate species Cunninghamia konishii (Hwang et al., 2003) had been studied based on cpDNA. Here we present the genetic variation of cpDNA of temperate representative of $T$. aralioides in Taiwan and its adjacent areas. We found that the data of cpDNA provided insights that were not detected in allozyme study (Wu et al., 2001). We postulate that north to central mountain area might be the major refugium of $T$. aralioides in Taiwan during the last glaciations. These results also indicate that the phylogeographical patterns of $T$. aralioides, a temperate tree species, do not conform to that of Cyclobalanopsis glauca, a subtropical tree species (Huang et al., 2002).

\section{MATERIALS AND METHODS}

\section{Sampling}

A total of 24 populations were sampled including 20 from Taiwan, two each from the Ryukyus and Japan (Fig. 1; Table 1). For the analysis of cpDNA, each population was represented by four individuals because it was shown that 2.5 individuals per population yield the minimum variance for $G_{\mathrm{st}}$ at haploid locus regardless of the number of populations studied (Pons \& Petit, 1995). Fresh leaves were collected from each individual tree, and they were desiccated with silica gel and then stored in a freezer $\left(-30^{\circ} \mathrm{C}\right)$ permanently after complete dryness, or they were stored in the freezer $\left(-70^{\circ} \mathrm{C}\right)$ directly.

\section{DNA sequencing}

The DNAs were extracted from the sample leaves by using the protocol of Murray and Thompson (1980). The DNA extracting solution was then used to amplify the markers for detecting the variation in polymerase chain reaction (PCR). Ten universal primer pairs had been screened to detect the variation among the population; only two markers were taken in this study, i.e. intergenic spacer of $p e t \mathrm{G}-\operatorname{trn} \mathrm{P}$ and petA-psbJ. The primers for petG-trnP are 5'-GGT CTA ATT CCT ATA ACT TTG GC- $3^{\prime}$ in forward and $5^{\prime}$-GGG ATG TGG CGC AGC TTG G- $3^{\prime}$ in reverse; and the primers for petA-ps $b$ J are $5^{\prime}$-GGA GAT GCA GAG ATA GTA C-3'in forward and 5'-CTC TTT GGT TGA TAG GTA CTG-3' in reverse. Thirty-four thermal cycles were given for amplification. The annealing temperature is $55{ }^{\circ} \mathrm{C}$ for $45 \mathrm{~s}$ for pet $\mathrm{G}-\operatorname{trn} \mathrm{P}$ and $50{ }^{\circ} \mathrm{C}$ for $90 \mathrm{~s}$ for pet $\mathrm{A}-$ $p s b \mathrm{~J}$. The extension temperature is $72{ }^{\circ} \mathrm{C}$ for $60 \mathrm{~s}$ for pet $\mathrm{G}$ trn $\mathrm{P}$ and $72{ }^{\circ} \mathrm{C}$ for $90 \mathrm{~s}$ for pet $\mathrm{A}-p s b \mathrm{~J}$. The PCR products were then purified with the commercial kit and then sequenced with a sequencer ABI3100 using Big Dye terminator (Applied Biosystem, California, USA).

\section{Sequence analysis}

The DNA sequences were aligned by eye. Construction of haplotype network was then performed by TCS (version 1.3), as described by Clement et al. (2000). Haplotype diversity (h), nucleotide diversity per site $(\pi)$ (Nei, 1987), tests of neutrality including Tajima's (1989) D, Fu \& Li's (1993) $D^{*}$ and $F$, and the determination of their associated significance were performed using the DnaSP program (Rozas \& Rozas, 1999). 
Figure 1 Distribution of haplotypes (A-H) of Trochodendron aralioides in Taiwan and its adjacent areas. 1, Asiu; 2, Chomonkyo; 3, Amami; 4, Iriomote; 5, Yangmingshan; 6, Shihting; 7, Nanchatienshan; 8, Chilanshan; 9, Hsiakeluoshan; 10, Hakannishan; 11, Taipingshan; 12, Ssuyuan; 13, Hoping; 14, Piluchi; 15, Meifeng; 16, Tanta; 17, Chitou; 18, Zueshui; 19, Tatachia; 20, Takuanshan; 21, Hsiangyang; 22, Tuona; 23, Tahanshan; 24, Lilongshan.

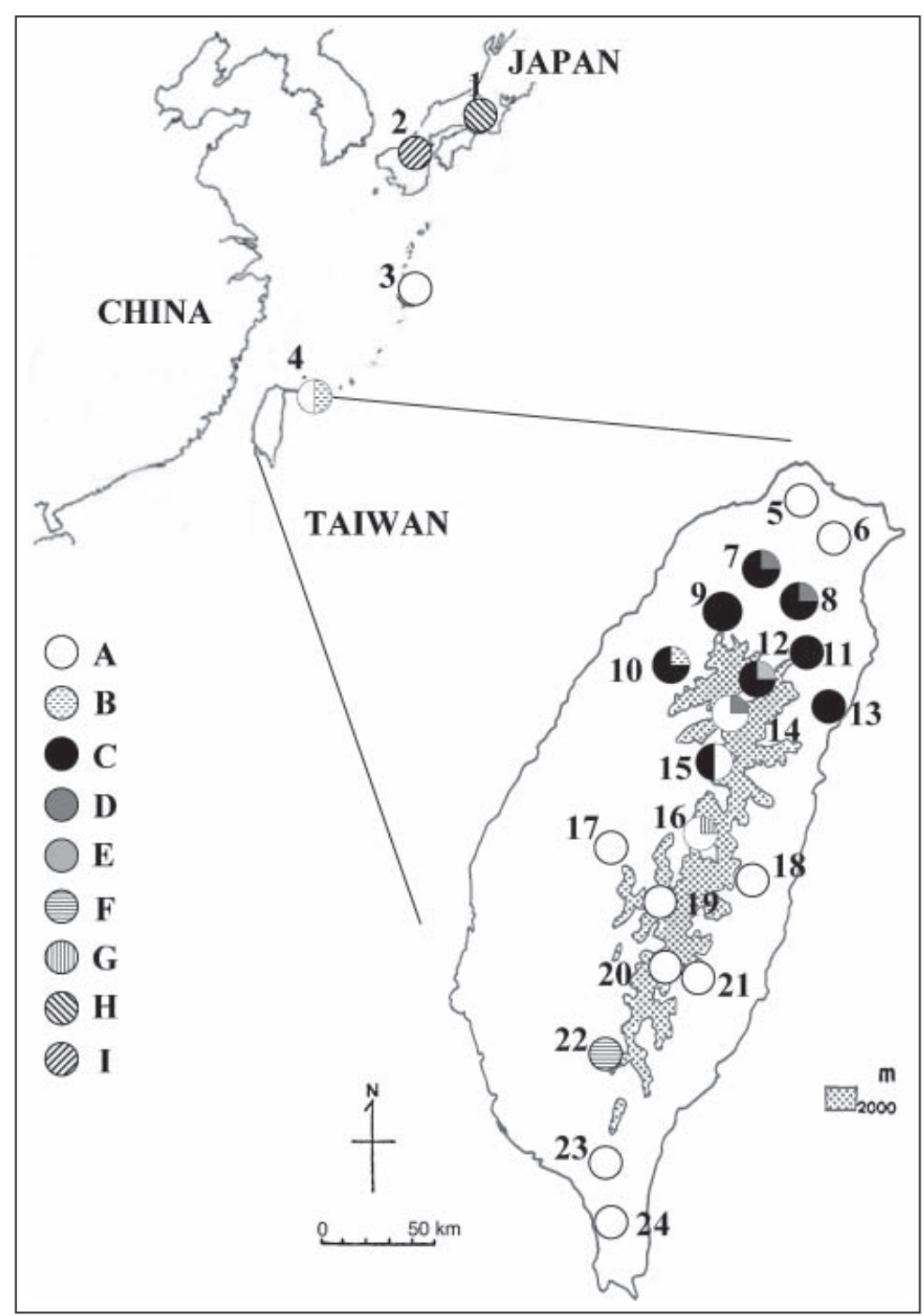

\section{Analyses of population structure}

Two parameters of differentiation of populations, $G_{\mathrm{st}}$ and $N_{\mathrm{st}}$, were analysed by HaploNst (Pons \& Petit, 1996). $G_{\text {st }}$ depends only on haplotype frequencies while $N_{\text {st }}$ is influenced by haplotype frequencies and genetic distance between haplotypes.

To examine the similarity of genetic stricture among populations, a maximum parsimony tree was reconstructed. A data matrix was made by taking population in each locality as an OTU (operational taxonomic unit) and haplotypes and haplotype lineages as characters. Character state codes 0 when haplotype or lineage was absent, and codes 1 to 4 depending on how many individuals hold such haplotype (lineage) in this population. The data matrix was then performed with PAUP $^{\star}$ version $4.0 \mathrm{~b} 10$ (Swofford, 2000) with characters being set in order, and the parsimony being selected for generating a tree. Resampling was performed with bootstrap for 1000 replicates.

\section{RESULTS}

\section{Sequence analysis}

Among the sequences of intergenic spacer of petG-trnP (350 bp, GenBank accession numbers AY294754-AY294848), no indels (insertion-deletion) but four substitutions were detected (Table 2). Among the sequences of intergenic spacer of petA-psb (752 bp, GenBank accession numbers AY294659AY294753), two substitutions were detected at position 143 for CT transition, and 570 for AC transversion. The other mutations include one inversion and many short indels. Among indels, polyA and polyT were excluded as polymorphic sites. The following are positions of polyA and polyT that show indels: 80 and $520-521$ for polyA and $152-153$ for polyT. The other indels are detected as follows: 154-157 for ATTT, 329 for A, and 332-335 for CTAT. The mutation at positions 684-694 for $5^{\prime}$-GAACAAACAAA- ${ }^{\prime}$ and $5^{\prime}$-TTTGTTTGTTC- $3^{\prime}$ is 


\begin{tabular}{|c|c|c|c|c|}
\hline Locality and population no. & Latitude-longitude & $\begin{array}{l}\text { Altitude } \\
\text { (m) }\end{array}$ & $\begin{array}{l}\text { Sample } \\
\text { size }\end{array}$ & $\begin{array}{l}\text { Haplotype } \\
\text { (sample no.) }\end{array}$ \\
\hline \multicolumn{5}{|l|}{ Japan } \\
\hline 1 Asiu & $35^{\circ} 00^{\prime} \mathrm{N}-135^{\circ} 42^{\prime} \mathrm{E}$ & 700 & 4 & $\mathrm{H}(4)$ \\
\hline 2 Chomonkyo & $34^{\circ} 23^{\prime} \mathrm{N}-131^{\circ} 20^{\prime} \mathrm{E}$ & 150 & 4 & $\mathrm{I}(4)$ \\
\hline \multicolumn{5}{|l|}{ Ryukyus } \\
\hline 3 Amami & $28^{\circ} 24^{\prime} \mathrm{N}-129^{\circ} 42^{\prime} \mathrm{E}$ & 500 & 3 & $\mathrm{~A}(3)$ \\
\hline 4 Iriomote & $24^{\circ} 25^{\prime} \mathrm{N}-123^{\circ} 45^{\prime} \mathrm{E}$ & 100 & 4 & $\mathrm{~A}(2) \mathrm{B}(2)$ \\
\hline \multicolumn{5}{|l|}{ Taiwan } \\
\hline 5 Yangmingshan & $25^{\circ} 10^{\prime} \mathrm{N}-121^{\circ} 34^{\prime} \mathrm{E}$ & 700 & 4 & $\mathrm{~A}(4)$ \\
\hline 6 Shihting & $24^{\circ} 59^{\prime} \mathrm{N}-121^{\circ} 40^{\prime} \mathrm{E}$ & 400 & 4 & $\mathrm{~A}(4)$ \\
\hline 7 Nanchatienshan & $24^{\circ} 46^{\prime} \mathrm{N}-121^{\circ} 24^{\prime} \mathrm{E}$ & 1600 & 4 & $\mathrm{C}(3) \mathrm{D}(1)$ \\
\hline 8 Chilanshan & $24^{\circ} 41^{\prime} \mathrm{N}-121^{\circ} 20^{\prime} \mathrm{E}$ & 1550 & 4 & $\mathrm{C}(3) \mathrm{D}(1)$ \\
\hline 9 Hsiakeluoshan & $24^{\circ} 34^{\prime} \mathrm{N}-121^{\circ} 12^{\prime} \mathrm{E}$ & 2000 & 4 & $\mathrm{C}(4)$ \\
\hline 10 Hakannishan & $24^{\circ} 32^{\prime} \mathrm{N}-121^{\circ} 02^{\prime} \mathrm{E}$ & 1600 & 4 & $\mathrm{~B}(1) \mathrm{C}(3)$ \\
\hline 11 Taipingshan & $24^{\circ} 30^{\prime} \mathrm{N}-121^{\circ} 32^{\prime} \mathrm{E}$ & 1800 & 4 & $\mathrm{C}(4)$ \\
\hline 12 Ssuyuan & $24^{\circ} 24^{\prime} \mathrm{N}-121^{\circ} 21^{\prime} \mathrm{E}$ & 1900 & 4 & $\mathrm{C}(3) \mathrm{E}(1)$ \\
\hline 13 Hoping & $24^{\circ} 18^{\prime} \mathrm{N}-121^{\circ} 39^{\prime} \mathrm{E}$ & 1200 & 4 & $\mathrm{C}(4)$ \\
\hline 14 Piluchi & $24^{\circ} 13^{\prime} \mathrm{N}-121^{\circ} 17^{\prime} \mathrm{E}$ & 2400 & 4 & $\mathrm{~A}(3) \mathrm{D}(1)$ \\
\hline 15 Meifeng & $24^{\circ} 06^{\prime} \mathrm{N}-121^{\circ} 11^{\prime} \mathrm{E}$ & 2000 & 4 & $\mathrm{~A}(2) \mathrm{C}(2)$ \\
\hline 16 Tanta & $23^{\circ} 46^{\prime} \mathrm{N}-121^{\circ} 07^{\prime} \mathrm{E}$ & 2450 & 4 & $\mathrm{~A}(3) \mathrm{G}(1)$ \\
\hline 17 Chitou & $23^{\circ} 40^{\prime} \mathrm{N}-120^{\circ} 47^{\prime} \mathrm{E}$ & 1700 & 4 & $\mathrm{~A}(4)$ \\
\hline 18 Zueshui & $23^{\circ} 32^{\prime} \mathrm{N}-121^{\circ} 16^{\prime} \mathrm{E}$ & 1500 & 4 & $\mathrm{~A}(4)$ \\
\hline 19 Tatachia & $23^{\circ} 30^{\prime} \mathrm{N}-120^{\circ} 52^{\prime} \mathrm{E}$ & 2500 & 4 & $\mathrm{~A}(4)$ \\
\hline 20 Takuanshan & $23^{\circ} 17^{\prime} \mathrm{N}-120^{\circ} 56^{\prime} \mathrm{E}$ & 2500 & 4 & $\mathrm{~A}(4)$ \\
\hline 21 Hsiangyang & $23^{\circ} 15^{\prime} \mathrm{N}-120^{\circ} 58^{\prime} \mathrm{E}$ & 2350 & 4 & $\mathrm{~A}(4)$ \\
\hline 22 Tuona & $22^{\circ} 53^{\prime} \mathrm{N}-120^{\circ} 46^{\prime} \mathrm{E}$ & 1800 & 4 & $\mathrm{~F}(4)$ \\
\hline 23 Tahanshan & $22^{\circ} 25^{\prime} \mathrm{N}-120^{\circ} 43^{\prime} \mathrm{E}$ & 1500 & 4 & $\mathrm{~A}(4)$ \\
\hline 24 Lilongshan & $22^{\circ} 10^{\prime} \mathrm{N}-120^{\circ} 43^{\prime} \mathrm{E}$ & 900 & 4 & $\mathrm{~A}(4)$ \\
\hline
\end{tabular}

Table 1 Sampling localities chosen for the population study of Trochodendron aralioides accompanied with sample sizes and their haplotypes

Table 2 Nine haplotypes of Trochodendron aralioides were recognized based on the distribution of polymorphic sites in the intergenic spacers of pet $\mathrm{G}-t r n \mathrm{P}$ and $p e t \mathrm{~A}-p s b \mathrm{~J} c p \mathrm{DNA}$

\begin{tabular}{|c|c|c|c|c|c|c|c|c|c|c|}
\hline \multirow[b]{2}{*}{ Haplotype } & \multicolumn{5}{|c|}{ petG-trnP } & \multicolumn{4}{|l|}{ petA-psbJ } & \multirow[b]{2}{*}{ Distribution } \\
\hline & 162 & 239 & 252 & 376 & 143 & $154-157$ & $329-335$ & 570 & $684-694$ & \\
\hline A & G & $\mathrm{C}$ & $\mathrm{T}$ & G & $\mathrm{T}$ & - & AATCTAT & $\mathrm{A}$ & GAACAAACAAA & Taiwan, Ryukyu \\
\hline B & G & $\mathrm{C}$ & $\mathrm{T}$ & G & $\mathrm{T}$ & - & AATCTAT & A & TTTGTTTGTTC* & Taiwan, Ryukyu \\
\hline $\mathrm{C}$ & G & $\mathrm{C}$ & $\mathrm{C}$ & G & $\mathrm{T}$ & - & AATCTAT & A & GAACAAACAAA & Taiwan \\
\hline $\mathrm{D}$ & G & $\mathrm{C}$ & $\mathrm{C}$ & A & $\mathrm{T}$ & - & AATCTAT & A & GAACAAACAAA & Taiwan \\
\hline $\mathrm{E}$ & G & $\mathrm{C}$ & $\mathrm{C}$ & A & $\mathrm{T}$ & - & AATCTAT & A & TTTGTTTGTTC* & Taiwan \\
\hline $\mathrm{F}$ & G & $\mathrm{C}$ & $\mathrm{T}$ & G & $\mathrm{T}$ & - & $-\mathrm{AT}--$ & A & GAACAAACAAA & Taiwan \\
\hline G & G & $\mathrm{C}$ & $\mathrm{T}$ & G & $\mathrm{T}$ & - & AATCTAT & $\mathrm{C}$ & GAACAAACAAA & Taiwan \\
\hline $\mathrm{H}$ & G & $\mathrm{T}$ & $\mathrm{T}$ & G & $\mathrm{C}$ & ATTT & AATCTAT & A & GAACAAACAAA & Japan \\
\hline I & $\mathrm{C}$ & $\mathrm{T}$ & $\mathrm{T}$ & G & $\mathrm{C}$ & ATTT & AATCTAT & $\mathrm{A}$ & GAACAAACAAA & Japan \\
\hline
\end{tabular}

${ }^{*}$ Inversion due to intramolecular recombination.

probably not resulted from base pair changes but apparently an inversion, and this may be due to intramolecular recombination as described in oak trees (Dumolin-Lapègue et al., 1998) by forming a 13 bp stem-loop hairpin (Fig. 2).

\section{Haplotypes and their distribution}

On the basis of 95 sequences with 1102 sites, a total of nine haplotypes were detected (Table 2; Fig. 1), and the relationship among these haplotypes is shown in Fig. 3. We consider base pairs from 684 to 694 of petA-psbJ are due to intramolecular recombination that is considered as a single evolutionary event, so inversion is weighted equally as a single base pair change. Type A is the most common and widely distributed in the Ryukyus, the northern tip of Taiwan including Yangmingshan and Shihting, and central and southern Taiwan. Type $\mathrm{C}$ is the next common haplotype restricted to the northern Taiwan including Hsueshan Range and to the northern Central 


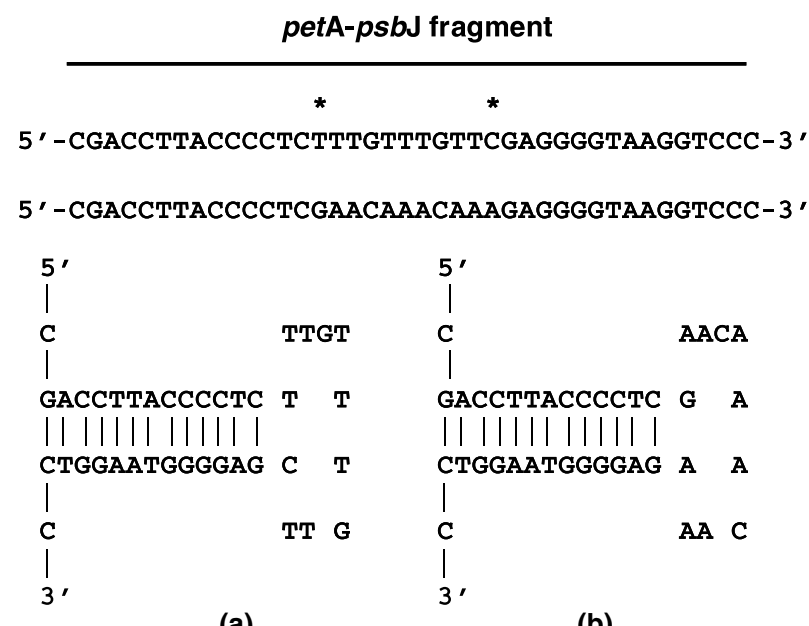

(a)

(b)

Figure 2 Intramolecular recombination leading to inversion occurs in intergenic spacer of petA-psbJ cpDNA of Trochodendron aralioides in a stem-loop hairpin with 13 pair's nucleotide as stem and 11 nucleotides as loop. Asterisk indicates the fragment that shows inversion.

Mountain Ridge (Fig. 1). Type D is derived from type C due to a substitution and this type spreads in Nanchatienshan, Chilanshan and Piluchi. Type $\mathrm{E}$ is derived from type $\mathrm{D}$ due to an inversion and this type is a singleton at Ssuyuan. Type B is derived from type A by an inversion and this type is found in the populations of Iriomote Island (Ryukyu) and Hakannishan (Taiwan). Type $\mathrm{F}$ is also derived from type $\mathrm{A}$ due to a deletion at position 329-335 of petA-psbJ and this type is entirely restricted to Tuona. Type $G$ is a singleton and is derived from type A due to a substitution and this type is only found in Tanta. Japanese populations are quite different from others, and they are represented by types $\mathrm{H}$ and $\mathrm{I}$; type $\mathrm{H}$ is restricted to Asiu, whereas type I is confined at Chomonkyo.

\section{Diversity of haplotype and nucleotide}

The haplotype diversity $(h)$ is 0.658 and the nucleotide diversity per site $(\pi)$ is 0.00088 for all populations, 0.595 and 0.00052 for Taiwan's population, 0.571 and 0.00040 for Japan's populations, and 0.476 and 0.00033 for the Ryukyus' population (Table 3). Parameters of Japan are underestimated due to low representatives in this study. Regarding local populations, only Ryukyus' Iriomote Island, and Taiwan's Nancha-

tienshan, Chilanshan, Hakannishan, Ssuyuan, Piluchi, Meifeng and Tanta are polymorphic, whereas the remaining local populations are monomorphic. Selection was not detected to play a role in shaping the genetic structure because the sequence variation did not deviate from the expectation of neutral selection when neutrality tests were performed using Tajima's $D$ test, $\mathrm{Fu}$ and Li's $D^{\star}$ and $F$ tests (Table 3 ).

\section{Analyses of population structure in Taiwan}

Population differentiation according to cpDNA variation was 0.700 and 0.542 for $G_{\text {st }}$ and $N_{\text {st }}$, respectively, and both the values were significantly higher than zero (Table 4). This suggests that the differentiation is strong among populations in Taiwan. These values were much greater than the $F_{\text {st }}$ reported from isozyme study $\left(F_{\mathrm{st}}=0.10\right.$, Wu et al., 2001) indicating gene flow via seed dispersal were limited.

A tree revealing similarity of genetic structure among populations is shown in Fig. 4. Japan's populations can be separated from the populations of the Ryukyus and Taiwan, and this is supported by bootstrap value of 89 . In Taiwan, two major groups of populations can be recognized. One is restricted to northern Taiwan between latitudes $24^{\circ} 46^{\prime}$ and $24^{\circ} 06^{\prime} \mathrm{N}$, and the other is distributed widely. The restricted group shares the haplotype $\mathrm{C}$ and its derivatives, D and E (Fig. 3). The other group shares haplotype A and its derivatives, F and G (Fig. 3). However, Meifeng's population is collapsed in bootstrap majority consensus tree (Fig. 4), indicating an overlapping position of Meifeng between these two groups as it contains both haplotypes $\mathrm{A}$ and $\mathrm{C}$ equally. The populations of the Ryukyus are nested inside the group that is distributed widely in Taiwan.

\section{DISCUSSION}

\section{Intramolecular recombination}

Among the polymorphic sites that distinguish haplotypes, substitutions and indels are associated without any redundancy while inversion due to intramolecular recombination (Fig. 2) appears redundantly in types B and E (Fig. 3). This implies that the loop inversion in the secondary structure is likely to occur in chloroplastic DNA repeatedly, as in the case of mitochondrial DNA in oaks (Dumolin-Lapègue et al., 1998). We consider the inversion found in few individuals in remote populations to be the result of gene flow or homoplasy. If the assumption of gene

Figure 3 Genealogy of haplotypes (A-I) of Trochodendron aralioides modified from the results of TCS program. Each arrow stands for one mutation including substitutions and indels between haplotypes. Types $\mathrm{H}$ and I are restricted to Japan while the other types

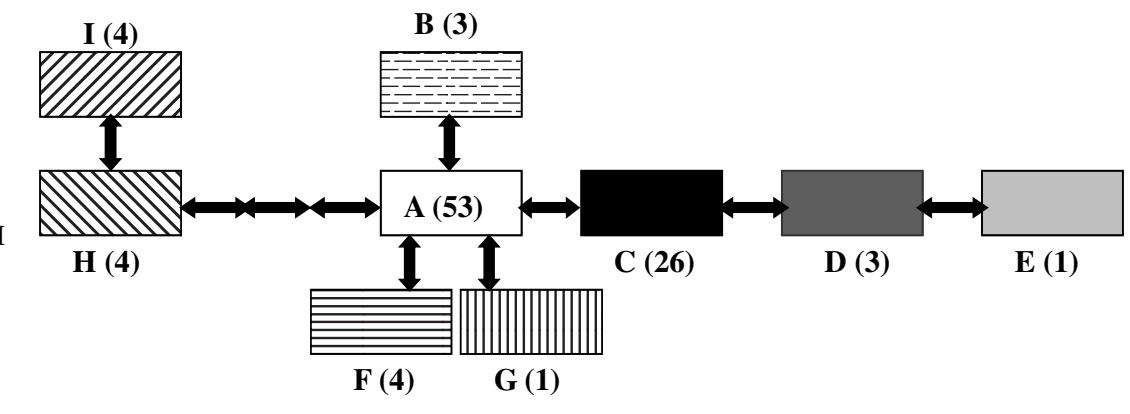
Number of individuals containing such haplotype are in parentheses. 


\section{S.-F. Huang et al.}

Table 3 Populations of Trochodendron aralioides with haplotype and nucleotide diversity associated with the results of neutrality tests based on intergenic spacers of petA-psbJ and petG-trnP cpDNA

\begin{tabular}{|c|c|c|c|c|c|}
\hline Populations & $\begin{array}{l}\text { Haplotype } \\
\text { diversity }(h)\end{array}$ & $\begin{array}{l}\text { Nucleotide } \\
\text { diversity }(\pi) \\
\text { (per site) }\end{array}$ & $\begin{array}{l}\text { Tajima's } D \\
\text { ( } P \text { value })\end{array}$ & $\begin{array}{l}\text { Fu and Li's } \\
D^{*}(P \text { value })\end{array}$ & $\begin{array}{l}\text { Fu and Li's } \\
F(P \text { value })\end{array}$ \\
\hline Total & $0.658 \pm 0.040$ & $0.00088 \pm 0.00012$ & $-0.72(P>0.1)$ & $0.58(P>0.1)$ & $-2.07(P>0.1)$ \\
\hline Japan & $0.571 \pm 0.089$ & $0.00040 \pm 0.00007$ & $1.44(P>0.1)$ & $0.89(P>0.1)$ & $0.97(P>0.1)$ \\
\hline 1 Asiu & 0.000 & 0.00000 & & & \\
\hline 2 Chomonkyo & 0.000 & 0.00000 & & & \\
\hline Ryukyu & $0.476 \pm 0.171$ & $0.00033 \pm 0.00012$ & $0.56(P>0.1)$ & $0.95(P>0.1)$ & $0.59(P>0.1)$ \\
\hline 3 Amami & 0.000 & 0.00000 & & & \\
\hline 4 Iriomote & $0.667 \pm 0.204$ & $0.00047 \pm 0.00014$ & & & \\
\hline Taiwan & $0.595 \pm 0.040$ & $0.00052 \pm 0.00006$ & $-0.59(P>0.1)$ & $0.02(P>0.1)$ & $-2.49(P>0.1)$ \\
\hline 5 Yangmingshan & 0.000 & 0.00000 & & & \\
\hline 6 Shihting & 0.000 & 0.00000 & & & \\
\hline 7 Nanchatienshan & $0.500 \pm 0.265$ & $0.00035 \pm 0.00019$ & & & \\
\hline 8 Chilanshan & $0.500 \pm 0.265$ & $0.00035 \pm 0.00019$ & & & \\
\hline 9 Hsiakeluoshan & 0.000 & 0.00000 & & & \\
\hline 10 Hakanishan & $0.500 \pm 0.265$ & $0.00070 \pm 0.00037$ & & & \\
\hline 11 Taipingshan & 0.000 & 0.00000 & & & \\
\hline 12 Ssuyuan & $0.500 \pm 0.265$ & $0.00070 \pm 0.00037$ & & & \\
\hline 13 Hoping & 0.000 & 0.00000 & & & \\
\hline 14 Piluchi & $0.500 \pm 0.265$ & $0.00070 \pm 0.00037$ & & & \\
\hline 15 Meifeng & $0.667 \pm 0.204$ & $0.00047 \pm 0.00014$ & & & \\
\hline 16 Chitou & 0.000 & 0.00000 & & & \\
\hline 17 Tanta & $0.500 \pm 0.265$ & $0.00035 \pm 0.00019$ & & & \\
\hline 18 Zueshui & 0.000 & 0.00000 & & & \\
\hline 19 Tatachia & 0.000 & 0.00000 & & & \\
\hline 20 Takuanshan & 0.000 & 0.00000 & & & \\
\hline 21 Hsiangyang & 0.000 & 0.00000 & & & \\
\hline 22 Tuona & 0.000 & 0.00000 & & & \\
\hline 23 Tahanshan & 0.000 & 0.00000 & & & \\
\hline 24 Lilongshan & 0.000 & 0.00000 & & & \\
\hline
\end{tabular}

Table 4 Analysis of population structure of Trochodendron aralioides in Taiwan

\begin{tabular}{lccc}
\hline $\begin{array}{l}\text { Diversity } \\
\text { parameter }\end{array}$ & Value (SD) & $\begin{array}{l}\text { Test value } \\
(U)\end{array}$ & $P$ value \\
\hline$H_{\mathrm{s}}$ & $0.183(0.0579)$ & & \\
$H_{\mathrm{t}}$ & $0.611(0.0673)$ & & $<0.01$ \\
$G_{\text {st }}$ & $0.700(0.0876)$ & 7.99 & \\
$V_{\mathrm{s}}$ & $0.279(0.1492)$ & & $<0.01$ \\
$V_{\mathrm{t}}$ & $0.607(0.2074)$ & & $>0.05$ \\
$N_{\text {st }}$ & $0.542(0.1929)$ & 2.809 & \\
$N_{\text {st }}-G_{\text {st }}$ & $-0.158(0.1646)$ & -0.96 & \\
\hline
\end{tabular}

$H_{\mathrm{s}}$ and $V_{\mathrm{s}}$, intrapopulation diversity.

$H_{\mathrm{t}}$ and $V_{\mathrm{t}}$, total diversity.

$G_{\mathrm{st}}$ and $N_{\mathrm{st}}$, degree of differentiation between populations.

flow were true, we shall expect similar haplotype composition in the populations involved and the same haplotype containing the sequence of inversion exiting in the populations. But the haplotype composition found in these two remote populations was quite different, and inversion was found in two different haplotypes. Homoplasy is more likely the answer. Although the structure of sequence tends to form a loop within the molecule, only few individuals containing inversion were found in remote populations is probably the small sample size we used in this study. Further investigation using large number size might be able to evaluate the frequency of inversion and answer whether inversion is due to homoplasy.

\section{Centre of genetic diversity of $\boldsymbol{T}$. aralioides in Taiwan}

Genetic diversity in a population is accumulated either from newly evolved alleles and/or from other sources that join the population. Thus an area showing higher genetic diversity could imply that (i) this area could have been a refugium: an area with a stable ecological habitat during the fluctuation of environmental change that led to the accumulation of genetic diversity (Tzedakis et al., 2002), or (ii) this area could be an intermediate zone that received organisms from different sources and resulting in higher genetic diversity than in each of the original sources. In the first case, haplotypes within this area are closely related, whereas in the latter case haplotypes may include those that are distantly related. According to 


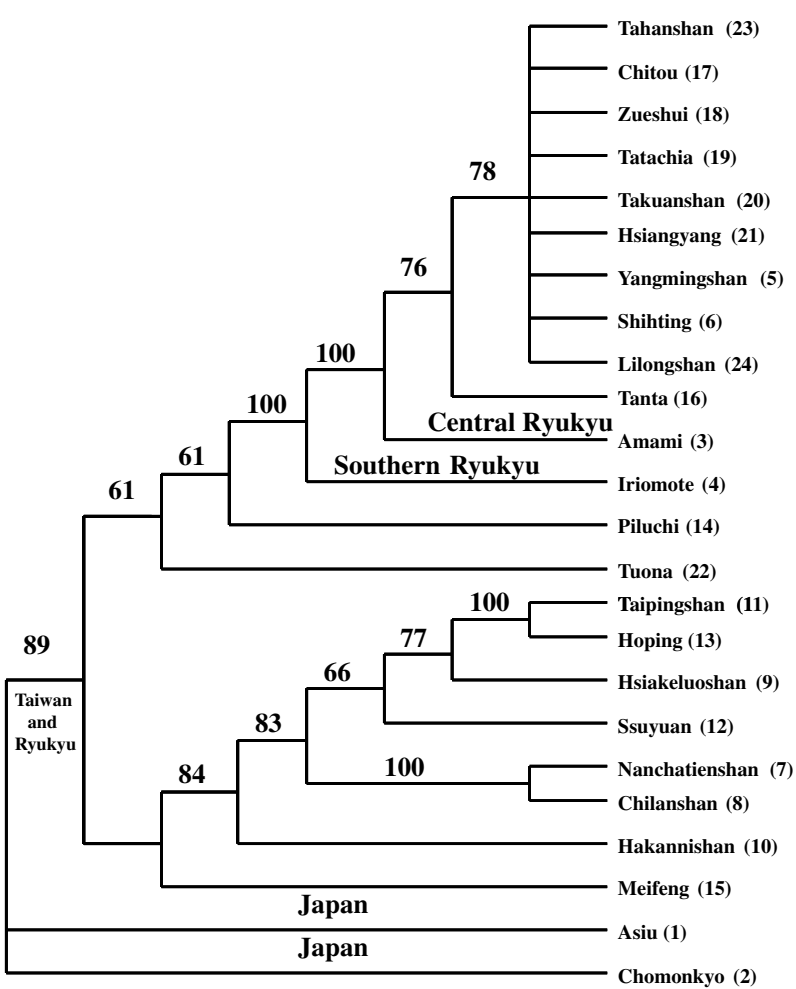

Figure 4 The maximum parsimony tree showing similarity of populations of Trochodendron aralioides generated from computer program PAUP $^{\star}$ version 4.10 based on frequency of haplotypes and lineage of cpDNA with criterion of maximum parsimony. Bootstrap values that were obtained by resampling for 1000 replicates are on branches where asterisk is less than $50 \%$. Shaded horizontal line shows two major groups of population can be differentiated in Taiwan.

cpDNA polymorphism, higher genetic diversity in T. aralioides in Taiwan is located in the latitudes between $24^{\circ} 06^{\prime}$ and $24^{\circ} 46^{\prime} \mathrm{N}$ where five haplotypes of seven were found, and haplotypes C, D and E were restricted there. Moreover, $\pi$ is higher in Hakannishan, Piluchi and Ssuyuan (Table 3) areas within the range of this area. Thus, this area is a centre of genetic diversity and was possibly a shelter in Taiwan for $T$. aralioides during the Quaternary glacial period. This area is consistent with the finding of Cunninghamia konishii, a temperate species endemic in central and northern Taiwan, as Kuanwu and Tajian, within the range of the possible refugium, were most diversified and thought to be the recolonized places from Asian continent (Hwang et al., 2003).

A primary refugium in central Taiwan below latitude $24^{\circ} 06^{\prime} \mathrm{N}$ was proposed by Lin (2001) according to the expected heterozygosity of allozyme data of eight distantly related species including T. aralioides, although the possibility of the occurrence of other refugia in Taiwan was not excluded. Regarding allozyme data, genetic diversity measures are mainly described by allele richness and expected heterozygosity (El Mousadik \& Petit, 1996; Comps et al., 2001; Widmer \& Lexer, 2001). Allele richness deals with rare alleles while heterozygosity deals with common alleles. It is hypothesized that a population first colonizes a place from a source area (refugium) by a few individuals (founder event). During the colonization, rare alleles occur in few individuals and are easily drifted away while the common alleles are many and hence have more chance to colonize this place. Thus it is predicted that allele richness decreases with distance from the source area (El Mousadik \& Petit, 1996; Comps et al., 2001). In contrast, a place may receive individuals from different sources resulting higher heterozygosity than expected (Comps et al., 2001). Thus inference of a possible refugium can be proposed by the measure of allele richness and expected heterozygosity, but attention should be paid to expected heterozygosity.

According to the data of allozymes, allele richness of T. aralioides in Taiwan is the highest in Meifeng, followed by Hsiangyang and Yuanyang Lake (near Chilanshan) while the expected heterozygosity is the highest in Chitou followed by Nantou, Alishan, Rhkeshan (near Shihting) and Lalashan (near Nanchatienshan) (Table 5). According to the allele richness and expected heterozygosity of allozymes, we may conclude that there are two centres of diversity of the Nantou area and the Lalashan-Yuanyang Lake area. The proposed centre of genetic diversity based on cpDNA is not matched completely with that based on isozyme. The possible causes are as follows. Calculation of heterozygosity of allozyme is according to allele frequency in a population. Greater number of allele and uniformity in the distribution of allelic frequency yield higher expected heterozygosity. However, nucleotide diversity $(\pi)$ is determined by percentage of substitution or polymorphic site in addition to haplotype frequency (Nei \& $\mathrm{Li}$, 1987). Thus a single allele of isozyme in a population could contain a lot of polymorphic site, which contributes to nucleotide diversity.

\section{Is Central Mountain Ridge a barrier between eastern and western populations of $T$. aralioides?}

Taiwan has more than 100 mountain peaks over $3000 \mathrm{~m}$ and most of them are located in the Central Mountain Range that extends from north to south. Thus it is likely that the Central Mountain Range could serve as a barrier between eastern and western populations. This is manifested by the study of Cyclobalanopsis glauca (Huang et al., 2002), a subtropical species distributed in the elevation from 50 to $1200 \mathrm{~m}$ in Taiwan. However, the barrier is not problematic to T. aralioides whose distribution is considerably higher in elevation, as indicated by the presence of haplotypes A and C on both sides of the Central Mountain Ridge. Although many high mountain peaks are located in the Central Mountain Ridge, saddles allow for dispersal to occur across the range and let populations penetrate through the barrier. Additionally, the temperature was $2{ }^{\circ} \mathrm{C}$ higher than today about 5000 years ago (Tsukada, 1966), so the distribution of T. aralioides in Taiwan would be distributed higher in elevation and have a better chance to transcend the barrier. 


\begin{tabular}{|c|c|c|c|c|c|c|}
\hline \multirow{2}{*}{$\begin{array}{l}\text { Populations in } \\
\text { allozyme study }\end{array}$} & \multirow{2}{*}{$\begin{array}{l}\text { Sample } \\
\text { size }\end{array}$} & \multicolumn{2}{|c|}{ Alleles/locus } & \multicolumn{2}{|c|}{ Heterozygosity } & \multirow{2}{*}{$\begin{array}{l}\text { Populations in } \\
\text { this study }\end{array}$} \\
\hline & & Observed & $\mathrm{R}_{(40)}{ }^{*}$ & Observed & Expected & \\
\hline Asiu & 20 & 1.71 & 1.71 & 0.188 & 0.226 & 1 Asiu \\
\hline Chomonkyo & 25 & 1.76 & 1.70 & 0.111 & 0.124 & 2 Chomonkyo \\
\hline Yangmingshan & 25 & 1.59 & 1.55 & 0.093 & 0.123 & 5 Yangmingshan \\
\hline Erkeshan & 23 & 1.59 & 1.59 & 0.133 & 0.153 & 6 Shihting \\
\hline Lalashan & 25 & 1.76 & 1.74 & 0.146 & 0.152 & 7 Nanchatienshan \\
\hline Yuanyang Lake & 27 & 2.00 & 1.90 & 0.131 & 0.130 & 8 Chilanshan \\
\hline Taipingshan & 25 & 1.88 & 1.82 & 0.127 & 0.130 & 11 Taipingshan \\
\hline Iriomote Island & 20 & 1.35 & 1.35 & 0.076 & 0.099 & 3 Iriomote Island \\
\hline Ssuyuan & 24 & 1.53 & 1.51 & 0.100 & 0.104 & 12 Ssuyuan \\
\hline Anmashan & 30 & 1.88 & 1.81 & 0.110 & 0.135 & \\
\hline Pilu & 31 & 1.88 & 1.82 & 0.131 & 0.125 & 14 Piluchi \\
\hline Meifeng & 24 & 2.12 & 2.01 & 0.115 & 0.106 & 15 Meifeng \\
\hline Nantou & 21 & 1.88 & 1.88 & 0.144 & 0.162 & 17 Tanta \\
\hline Chitou & 20 & 1.71 & 1.71 & 0.135 & 0.166 & 16 Chitou \\
\hline Alishan & 20 & 1.89 & 1.87 & 0.150 & 0.154 & 19 Tatachia \\
\hline Kuaiku & 23 & 1.76 & 1.74 & 0.132 & 0.135 & 22 Tuona \\
\hline Hsiangyang & 20 & 1.94 & 1.94 & 0.129 & 0.125 & 21 Hsiangyang \\
\hline Tahanshan & 27 & 1.76 & 1.69 & 0.102 & 0.091 & 23 Tahanshan \\
\hline Lilongshan & 27 & 1.71 & 1.64 & 0.092 & 0.086 & 24 Lilongshan \\
\hline
\end{tabular}

Table 5 Allele richness and heterozygosity of Trochodendron aralioides in each locality modified from the allozyme study of $\mathrm{Wu}$ et al. (2001, Table 3)

*Allele richness of each population when sampling size of all populations is equal to 20 individuals and the values of allele richness are obtained by performing the program rarefaction through the internet web site: http://www.pierroton.inra.fr/genetics/labo/Software/Rarefac/ index.html

\section{Temperate species has a different evolutionary history from subtropical species}

It is not unexpected that observation of subtropical tree species, like Cyclobalanopsis glauca (Huang et al., 2002) has different phylogeographical pattern from temperate species, like $T$. aralioides. As stated above, $T$. aralioides has higher genetic diversity in north to central mountainous area, and a possible refugium also occurring in this area, but C. glauca has many unique haplotypes in the east of the Central Mountain Range, and a possible refugium in southeastern part of Taiwan. The distinct effect of the Central Mountain Range on gene flow was also observed between east and west populations of these two species. It could be temperate species occurring in present habitat between 1500 and $2500 \mathrm{~m}$ would find an optimal growth habitat in lower elevations but not in the south part where subtropical climate prevailed in glaciation stage. This is the first time north-central region of Taiwan is clearly recognized as a diversity centre for temperate plant species. Furthermore temperate species will be tested to see whether north central region is a common hotspot.

\section{ACKNOWLEDGMENTS}

The authors thank the following Institutions and persons for their help in collecting samples: Mrs Meng-Huai Su and We-Hsiu Wu, Department of Botany, National Taiwan University (NTU), Taipei; Prof. Ping-Chung Kuan and Ms Tsung-I Chang, Department of Forestry, NTU; Dr Nien-Jun Chung and
Mr Te-Jen Chen, Experimental Forest, NTU, Chu-San; Dr Ching-Lung Yeh and Mr Jung-Chuan Yeh, Department of Forestry, National Pingtung University Science Technology, Pingtung; Dr Tsung-Hsin Hsieh, Department of Natural Science Education, National Tainan Teacher College, Tainan; Mr Tsai-Wen Hsu, Taiwan Endemic Species Research Institute, Nantou; Mr Hsi-Chou Hung, Luotung Branch, Taiwan Forestry Bureau, Luotung; Ms Ching-Hsian Chen, Hualien Branch, Taiwan Forestry Bureau, Hualien; Mr Ji-Chen Wu, Taiwan Forestry Research Institute, Taipei; Mrs Jin-Yuan Huang and Kuo-Kai Hsu, Graduate Institute of Biotechnology, Chinese Culture University, Taipei. This study was supported by the National Science Council (grant numbers NSC91-2313-B-002379 and NSC91-2811-B-002-057), Executive Yuan, Taiwan.

\section{REFERENCES}

Avise, J.A., Arnold, J., Ball, R.M., Bermingham, E., Lamb, T., Neigel, J.E., Reeb, C.A. \& Saunders, N.C. (1987) Intraspecific phylogeography: the mitochondria DNA bridge between population genetics and systematics. Annual Review of Ecology and Systematics, 18, 489-522.

Chaw, S.M. (1992) Pollination, breeding syndromes, and systematics of Trochodendron aralioides Sieb. \& Zucc. (Trochodendraceae), a relictual species in Eastern Asia. Phytogeography and botanical inventory of Taiwan (ed. by C.I. Peng), pp. 63-77. Institute of Botany, Monograph Series, Academia Sinica, Taipei. 
Clement, M., Posada, D. \& Crandall, K.A. (2000) TCS: a computer program to estimate gene genealogies. Molecular Ecology, 9, 1657-1669.

Comps, B., Gomory, D., Letouzey, J., Thiebaut, B. \& Petit, R.J. (2001) Diverging trends between heterozygosity and allele richness during postglacial colonization in the European beech. Genetics, 157, 389-397.

Dumolin-Lapègue, S., Pemonge, M.H. \& Petit, R.J. (1998) Association between chloroplast and mitochondria lineages in oaks. Molecular Biology and Evolution, 15, 1321-1331.

El Mousadik, A. \& Petit, R.J. (1996) High level of genetic differentiation for allelic richness among populations of the argan tree [Argania spinosa (L.) Skeels] endemic to Morocco. Theoretical and Applied Genetics, 92, 832-839.

Fu, Y.X. \& Li, W.H. (1993) Statistical tests of neutrality of mutations. Genetics, 133, 693-709.

Ho, C.S. (1982) Tectonic evolution of Taiwan-explanatory text of the tectonica map of Taiwan. The Ministry of Economic Affairs, Republic of China, Taipei, Taiwan.

Hsieh, C.F. (2002) Composition, endemism and phytogeographical affinities of the Taiwan flora. Taiwania, 47, 298-310.

Hsieh, C.F., Shen, C.F. \& Yang, K.C. (1994) Introduction to the flora of Taiwan, 3: floristics, phytogeography, and vegetation. Flora of Taiwan, 2nd edn, Vol. 1 (ed. by Editorial Committee of the Flora of Taiwan), pp. 7-18. Editorial Committee of the Flora of Taiwan, Taipei.

Huang, S.S.F., Hwang, S.Y. \& Lin, T.P. (2002). Spatial pattern of chloroplast DNA variation of Cyclobalanopsis glauca in Taiwan and eastern Asia. Molecular Ecology, 11, 2349-2458.

Hwang, S.Y., Lin, T.P., Ma, C.S., Lin, C.L., Chung, J.D. \& Yang, J.C. (2003) Postglacial population growth of Cunninghamia konishii (Cupressaceae) inferred from phylogeographical and mismatch analysis of chloroplast DNA variation. Molecular Ecology, 12, 2689-2695.

Lin, T.P. (2001) Allozyme variations in Michelia formosana (Kanehira) Masamune (Magnoliaceae), and the inference of a glacial refugium in Taiwan. Theoretical and Applied Genetics, 102, 450-457.

Lu, A.M., Li, J.Q. \& Chen, Z.D. (1993) The origin and dispersal of the lower Hamamelidae. Acta Phytotaxonomica Sinica, 31, 489-504.

Murray, M.G. \& Thomson, W.F. (1980) Rapid isolation of high molecular weight plant DNA. Nucleic Acids Research, 8, 4321-4325.

Nei, M. (1987) Molecular evolutionary genetics. Columbia University Press, New York.

Nei, M. \& Li, W.-H. (1987) Mathematical model for studying genetic variation in terms of restriction endonucleases. Proceedings of National Academy of the United States of America, 76, 5269-5273.

Pons, O. \& Petit, R.J. (1995) Estimation, variance and optimal sampling of gene diversity. I. Haploid locus. Theoretical and Applied Genetics, 90, 462-470.

Pons, O. \& Petit, R.J. (1996) Measuring and testing genetic differentiation with ordered versus unordered alleles. Genetics, 144, 1237-1245.
Rozas, J. \& Rozas, R. (1999) DnaSP, version 3: an integrated program for molecular population genetics and molecular evolution analysis. Bioinformatics Application Note, 15, 174175.

Shaw, C.L. (1996) Tectonic evolution of the CretaceousCenozoic basins of Taiwan. Annual Report of National Taiwan Museum, 39, 429-446 (in Chinese).

Swofford, D.L. (2000) Phylogenetic analysis using parsimony (and other methods), Ver. 4. Sinauer, Sunderland, MA.

Tajima, F. (1989) Statistical method for testing the neutral mutation hypothesis by DNA polymorphism. Genetics, 123, 585-595.

Tsukada, M. (1966) Late Pleistocene vegetation and climate in Taiwan (Formosa). Proceedings of National Academy of the United States of America, 55, 543-548.

Tzedakis, P.C., Lawson, I.T., Forgley, M.R. \& Hewitt, G.M. (2002) Buffered tree population changes in a Quaternary refugium: evolutionary implications. Science, 297, 2044-2047.

Widmer, A. \& Lexer, C. (2001) Glacial refugia: sanctuaries for allelic richness, but not for gene diversity. Trends in Ecology and Evolution, 16, 267-269.

Wu, J.E. (2001) Part I: Study on the biogeography and the genetic variation of Trochodendron aralioides; Part II: Phylogeny of Trochodendron aralioides and its allies in eastern Asia. Doctoral Dissertation, National Normal Taiwan University, Taipei.

Wu, J.E., Tung, W.F. \& Wang, J.C. (1999) Molecular phylogeny of the lower Hamamelidae based on nucleotide sequences of $t r n \mathrm{~L}$ intron in the chloroplast DNA. Biological Bulletin of National Taiwan Normal University, 34, 137-149.

Wu, J.E., Huang, S., Wang, J.C. \& Tong, W.F. (2001) Allozyme variation and the genetic structure of populations of Trochodendron aralioides, a monotypic and narrow geographic genus. Journal of Plant Research, 114, 45-57.

\section{BIOSKETCHES}

Shing-Fan Huang is a postdoc in the Institute of Plant Biology, National Taiwan University. His work mainly focuses on the phylogeny and phylogeography of vascular plants.

Shih-Ying Hwang is a professor in the Graduate Institute of Biotechnology, Chinese Culture University. He conducts projects related to the evolutionary genetics of conifers and other vascular plants using molecular markers.

Jenn-Che Wang is a professor in the Department of Biology, National Taiwan Normal University. His research interests are on the phylogeny of higher plants.

Tsan-Piao Lin is a professor in the Institute of Plant Biology, National Taiwan University. He is working on the population genetics and phylogeography of many native plant species of Taiwan. 